\title{
Menstruación decolonial
}

\author{
Núria Calafell Sala ${ }^{1,2}$ (iD 0000-0001-5706-4855 \\ 'Consejo Nacional de Investigaciones Científicas y Técnicas, Centro de \\ Investigaciones y Estudios sobre Cultura y Sociedad), Córdoba, Argentina. \\ ${ }^{2}$ Universidade Nacional de Córdoba, Córdoba, Argentina.
}

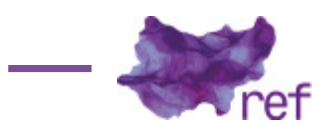

Resumen: La menstruación ha sido parte de una colonización patriarcal de los cuerpos a lo largo de la historia del pensamiento occidental. Desde hace aproximadamente cuatro años, sin embargo, una serie de propuestas vienen tensionando este proceso de colonización, en especial desde los territorios de Abya Yala. Este artículo focaliza en estos ejemplos, pertenecientes a la llamada Ginecología Natural, y encara su estudio a través de la exploración semiótica de dos cuestiones: por un lado, el lenguaje que estos discursos manejan en manuales, fanzines o páginas web; y, por el otro, el conocimiento que construyen y/o reivindican bajo las premisas de un empoderamiento femenino, de un autogestión de la salud y de un goce corporal.

Palabras clave: Ginecología Natural; menstruación; cuerpos; pensamiento decolonial.

\section{Menstruação decolonial}

Resumo: A menstruação foi parte de uma colonização patriarcal dos corpos ao longo da história do pensamento ocidental. Nos últimos quatro anos, entretanto, uma série de propostas vem tensionando tal processo de colonização, especialmente as nascidas em territórios de Abya Yala. Este artigo enfoca tais exemplos, pertencentes à chamada Ginecologia Natural, e estuda-os através da exploração semiótica de duas questóes: por um lado, a linguagem que esses discursos usam em manuais, fanzines ou páginas na internet; e por outro lado, o conhecimento que constroem e/ou reivindicam sob as premissas de um empoderamento feminino, de uma autogestão da saúde e de um gozo corporal. Palavras chave: Ginecologia Natural; menstruação; corpos; pensamento decolonial.

\section{Decolonial menstruating}

Abstract: Menstruation was part of a patriarchal colonization of bodies throughout the history of Western thought. In the past four years, however, a series of proposals has been straining such a colonization process, especially those born in the territories of Abya Yala. This article focuses on such examples that belong to the so-called Natural Gynecology, and analyses them through the semiotic exploration of two themes: on the one hand, the language that those discourses use in handbooks, fanzines or websites; on the other hand, the knowledge that they build and/or vindicate under the premises of female empowerment, health self-management and corporal pleasure.

Keywords: Natural Gynecology; Menstruation; Bodies; Decolonial thought.

\section{La Ginecología Natural en Abya Yala}

Aproximadamente la mitad de la población mundial menstrúa una vez al mes durante cuatro o siete días por un período de treinta o cuarenta años. Por una cuestión cultural, sin embargo, la eyección del fluido menstrual se ha convertido en una abyección, por lo que son muchas las personas que lo sienten como un tabú y muchas también quienes lo culpan de su exclusión como sujetos sociales. Ello ha derivado en distintos posicionamientos: desde quienes inician una búsqueda para detener el sangrado con la ayuda de la bio-medicina, apelando a su liberación y bienestar; hasta quienes lo reivindican como un signo de orgullo personal y pertenencia colectiva; pasando por quienes apuestan por seguir ocultándolo de la mirada del/a otro/a sin apenas cuestionarse el por qué ni el cómo. 
Dice la tradición que menstruar es un asunto doméstico (Ana VON REBEUR, 2012)' u obsceno, es decir, algo que debe quedar fuera de la escena visual, olfativa y táctil del/a otro/a y de uno/a mismo/a. Como un saber que se transmite de mujeres a niñas, la menstruación va significándose como el símbolo concreto y material de una marcación de género que, a su vez, está muy ligada al ámbito del parentesco, completamente privatizada y, por eso mismo, banalizada.

Cuando a finales de los años setenta Gloria Steinem (1978) se preguntaba qué pasaría si los hombres menstruaran, dejó bien claro que, más allá de las ironías, la menstruación es, como todo aquello que concierne a los cuerpos y a las corporalidades -más si éstas están heteronormativamente marcadas como femeninas- una cuestión de poder. Así, hablar del útero, de quiénes lo tienen, de cómo se relacionan con él, de cómo gestionan o no sus eyecciones no son cuestiones baladíes, puesto que, además de afectar a las relaciones intrapersonales, nos invitan a reubicar los límites al poder y a las personas que lo detentan en su necesidad de acceder a los cuerpos que desean.

Esta propuesta pretende, pues, reflexionar acerca de este último punto desde una perspectiva decolonial, para seguir reivindicando la menstruación como un objetivo dentro del feminismo.

Los antecedentes a nivel argentino de Eugenia Tarzibachi (2017), con su mirada transnacional sobre la industria del Femcare o el acercamiento más etnográfico de Karina Felitti (2016), sumado a los aportes internacionales de Chris Bobel (2010), con su análisis sobre políticas de la menstruación y feminismo; de Sharra Louise Vostral (2008), con una mirada más histórica de las tecnologías de higiene menstrual; del proyecto OBOS (Ourbodies, ourselves) del Boston Women's Health Collective (1970) para la recuperación de la soberanía / sabiduría corporal o de la comunidad cibernética "Soy1 soy4", de Erika Irusta (autodenominada la "primera pedagoga menstrual"); las meditaciones de corte más filosófico de Iris Marion Young (2005), o incluso las reflexiones de Mithu M. Sanyal (2012) alrededor de la palabra "vulva" en tanto que genital involucrado en la concepción positiva o negativa de la menstruación, ponen de manifiesto que ésta no es un mero fluido corporal, sino un fenómeno histórico-social que refleja los siguientes tres niveles constitutivos del ejercicio colonial:

-el del poder, desde el cual se niega el valor político y público de la menstruación y, por eso mismo, no se tiene en cuenta la implementación de políticas públicas adecuadas para la distribución equitativa, la adquisición gratuita y obligatoria, y la gestión informada y consciente de las tecnologías menstruales que hoy en día ofrece el mercado.

-el del saber, desde el cual se impone un único modo de acercarse al sangrado menstrual, el bio-médico, y se persiste no solo en ignorar otras formas más especulativas e incluso estéticas (como el llamado activismo menstrual; BOBEL, 2010), sino en negar (viejas) epistemologías otras basadas en conocimientos ancestrales, de raíz popular y espiritual, muy ligadas a la concepción especular del cuerpo y la naturaleza.

-el del género, desde el cual se construye una menstruación esencialmente femenina, al mismo tiempo que se impulsa a las nuevas mujeres -nuevas, por cuanto a ojos de la sociedad dejan de ser niñas para devenir "mujeres" y nuevas, por cuanto van redefiniéndose a medida que su participación en la esfera pública se hace cada vez más relevante- a una vivencia a-menstrual de sus menstruaciones, gracias a la cual pueden integrarse en la sociedad a la par que los hombres.

Atenta a esta multiplicidad de sentidos, en este trabajo se tomará la menstruación como eje desde el cual abordar un conjunto de discursos que tensionan o directamente resisten a estos modos de colonialidad. Me interesa muy especialmente analizar cómo se construye el cuerpo menstruante dentro del movimiento emergente de la Ginecología Natural (a partir de ahora GN), cuya importancia social se está dando a la par que otras manifestaciones ciudadanas surgidas tras el 3 de junio de 2015 ("Ni Una Menos"). Aunque el fenómeno es anterior a esta fecha, no se le ha dado el reconocimiento que amerita en sus dimensiones políticas y sociales, quizá por dos cuestiones: en primer lugar, porque, hasta hace apenas unos pocos años, era de pertenencia exclusiva al movimiento de mujeres, lo que dejaba de lado otras tantas experiencias permanentemente invisibilizadas de personas que, aun sin identificarse con el término "mujer", atraviesan corporalmente algunas de las cuestiones que son tratadas dentro de la GN. En segundo lugar, porque como todo lo que concierne a la mujer y a las identidades disidentes, se considera del ámbito de lo privado.

Si tenemos en cuenta que el núcleo de la GN es la menstruación como ciclo y como sangrado, se entiende este desplazamiento de la esfera de lo público y de lo político. Menstruar es "cosa de mujeres" (TARZIBACHI, 2017) y, sin embargo, el movimiento activista menstrual contemporáneo, con el que la GN camina de la mano, viene a decirnos todo lo contrario, al demandar más visibilidad, al denunciar el alto valor impositivo sobre los productos de gestión menstrual, o al promover formas nuevas para referirse al ciclo menstrual y a los estados emocionales que lo atraviesan. No es casual, en este sentido, que muchos de los trabajos que aquí se analizarán

'Así titula esta autora su libro: El asunto. La menstruación al desnudo. Como tendremos ocasión de ver a lo largo del artículo, esta opción discursiva de nombrar evasiva o eufemísticamente la menstruación no es menor a la hora de construir narrativas y saberes en las corporalidades menstruantes. 
sean el producto de talleres informativos (FANZINE COLECTIVX, 2015) o la herramienta que se utiliza para llevarlos a cabo (Pabla PÉREZ SAN MARTíN, 2015; Liliana POGLIANI, s.a.).

Si bien es cierto que su circulación sigue siendo menor con relación a la cantidad poblacional de cada territorio, este tipo de articulaciones van favoreciendo pequeñas pero decisivas transformaciones en el tejido sociocultural. Así, por ejemplo, he podido observar en mi participación a talleres sobre la temática que detrás de cada decisión individual hay también un cuestionamiento colectivo del saber/poder bio-médico en relación a la construcción del cuerpo de mujer patológico, lo que inevitablemente convierte a estos espacios en instancias de reflexión y debate acerca de cuestiones que van más allá de lo meramente ginecológico y afectan a la comprensión de la salud, del cuerpo reproductivo y, sobre todo, del "ser mujer" en las sociedades neoliberales del presente.

\section{Apunte metodológico}

Pocas cosas están tan profundamente patriarcalizadas, colonizadas y mercantilizadas como los cuerpos femeninos o feminizados. Ello, aplicado a los cuerpos menstruantes, supone la articulación de una "pedagogía de feminidad" (Rita Laura SEGATO, 2014, p. 61) en la que el cuerpo que menstrúa es desplazado a una condición femenina esencial y posicionado como inferior en una matriz binaria de género, jerárquica y opresiva:

[...] la posición masculina secuestra para sí la plataforma de enunciación de verdades de interés universal llamada "esfera pública" y se coloca en la posición de sujeto paradigmático de lo Humano pleno y englobante, en un gesto que expulsa a la posición femenina a la calidad de margen, resto, particularidad, cuestión de intimidad. (SEGATO, 2014, p. 62-63)

La sangre como resto que el cuerpo eyecta regularmente se convierte entonces en una metonimia, en el pretexto para promover, afianzar y naturalizar un conjunto de prácticas y discursos en torno a la menstruación, específicamente y, de manera general, en torno a las subjetividades y a los cuerpos que las representan. Por eso, es necesario reconocer estas cuestiones dentro de un marco de análisis simbólico y, sobre todo, como un campo profundamente minado por el patriarcado.

De hecho, si algo llama la atención cuando nos acercamos especulativamente a estos temas, es que ni la sangre menstrual ni la menstruación parecen ser procesos de agencia libre para quienes atraviesan por estas experiencias, sino que han sido culturalmente mediatizados $y$, las más de las veces, confinados según las circunstancias de cada época.

En este sentido, han existido desde siempre una serie de prescripciones en torno a la menstruación y a la gestión de la sangre menstrual, algunas de carácter moral, otras más técnicas. Eugenia Tarzibachi explica cómo todo ello se origina en el siglo XVIII, cuando la menstruación se constituye en un hecho médico, se feminiza y se patologiza, al mismo tiempo que se coloniza paulatinamente como saber corporal (TARZIBACHI, 2017, p. 53-66). Así, qué duración, qué frecuencia, qué tipo de sangrado, qué prácticas femeninas eran las mejores para manejar la sangre, qué comer, cómo dormir, qué actividades hacer en esos días, cómo higienizarse o cómo proteger el cuerpo de gérmenes en vistas a su única función vital, la maternidad (TARZIBACHI, 2017, p. 66; FELITTI, 2016, p. 177), fueron algunas de las pautas que circularon durante mucho tiempo.

Este artículo parte de estos supuestos para, desde una metodología de análisis crítico del discurso, proponer una descripción y una reflexión teórica acerca de aquellas categorías o conceptos que emergen dentro de la GN. Destaco, especialmente, algunos ejemplos escritos, seleccionados inductivamente a partir de las siguientes características: 1) todos ellos han sido producidos en AbyaYala2; 2) se han reeditado o publicado en los últimos cuatro años; 3) son de acceso abierto, es decir, pueden comprarse directamente (PÉREZ SAN MARTíN, 2015; POGLIANI, s.a.) o descargarse por Internet (FANZINE COLECTIVX, 2015; Lais SOUZA et al., 201 7); y 4) por la temática que los convoca (la GN), se relacionan entre sí y con otras ofertas afines a ellos, como son algunos libros para el público infanto-juvenil que también se mencionarán en el trabajo (Victoria de ABOITZ, 2014; May SERRANO; Marta SERRANO; Julia SERRANO, 2015; Violeta DEL RíO, 2016).

Asimismo, desde el año 2015 realizo un trabajo de campo participativo en talleres sobre GN en Córdoba Capital y alrededores. Durante estas experiencias, en las que formo parte de un grupo de bio-mujeres con gran pluralidad de perfiles (distintas edades, formaciones que oscilan entre el secundario y los estudios universitarios y terciarios, de clase media), he podido llevar a cabo una escucha atenta, así como distintas interlocuciones abiertas y espontáneas a modo de conversación. Como mujer menstruante y como ecofeminista radicada en uno de los territorios de Abya Yala, me he visto muy atravesada -biográfica y académicamente- por las discusiones y vivencias

${ }^{2}$ Este término procede de la lengua guna o kuna (de la etnia guna que habita entre los actuales Panamá y Colombia) y es utilizado por los/as dirigentes y comunicadores/as indgenas para marcar un posicionamiento político-ideológico bien concreto respecto al colonial "América". La decisión de utilizarlo en estas páginas obedece a la apuesta epistemológica del mismo, al encuerpamiento del proceso investigativo, pero también a la perspectiva decolonial de lectura y escritura. 
compartidas en estos encuentros. Por eso, en mis investigaciones actuales, no solo considero que son la base empírica sobre la que edificar estas elucubraciones, sino su único contexto de aplicación posible (Gregorio KLIMOVSKY, 1997).

Con ello quiero decir que la GN constituye una expresión sociocultural propia de un entorno occidental u occidentalizado ${ }^{3}$ de la clase media latinoamericana, de manera que no es extensiva a otras realidades. El hecho de que algunas prácticas de gestión menstrual, como el uso de material reutilizable, por ejemplo, especialmente las toallitas de algodón o de tela, sean compartidas en muchos lugares del mundo y por personas de distinta procedencia o condición social no significa que tengan el mismo significado ni que estén configuradas históricamente de la misma manera. No obstante, considero que la reivindicación de los modos de hacer(se), de pensar(se) y de habitar(se) (en) el mundo de quienes impulsan cambios (inter)personales puede ser un primer paso hacia la transformación de las circunstancias de vida de aquellas que no tienen más opciones ante la menstruación que asumirla como un estigma identitario.

\section{La Ginecología Natural: una propuesta epistemológica intersticial}

Es posible considerar el proyecto Ginecosofía. Sabiduría Ancestral de las Mujeres de la socióloga y partera tradicional chilena Pabla Pérez San Martín (2009) como el punto de partida del movimiento de la GN en Abya Yala, siendo su Manual introductorio a la Ginecología Natural (2015) y su recopilación Del cuerpo a las raíces. Uso de plantas medicinales para la salud sexual y reproductiva de las mujeres (2017), escrito en coautoría con Inés Cheuquelaf y Carla Cerpa (PÉREZ SAN MARTíN; CHEUQUELAF; CERPA, 2017), sus aportes más importantes. El hecho de que originalmente ambos trabajos hayan circulado por los ámbitos más alternativos del mercado editorial (en formato fanzine o desde editoriales autogestionadas) no ha sido impedimento para que su difusión haya sido amplia y transnacional.

Transnacional es también una posible genealogía del movimiento, que nos sitúa en el norte global con el Movimiento por la Liberación de las Mujeres (1960-1970) y su principal deriva: el movimiento self-help. Algunos de los elementos nucleares de debate y discusión de este movimiento son actualmente replicados por los manuales y fanzines que aquí se abordan. Así, se sigue planteando la resignificación de la menstruación en clave creativa y no -o no solo- reproductiva; se defienden el autoconocimiento, la autoexploración y el autocuidado como herramientas de reapropiación de un saber/poder corporal que se considera expropiado e ideológicamente colonizado; se visibiliza el placer carnal femenino; y se siguen denunciando los abusos de poder de la ginecología, una disciplina de la modernidad dominada por la mirada masculina.

Esto los lleva a desprenderse de algunas categorías como, por ejemplo, la de "normalidad" con relación a la frecuencia y a la duración del sangrado. Mientras la matemática médica establece una regularidad de 4 días cada 28-35 días, en estas propuestas se insiste mucho en la necesidad de dilatar los valores numéricos. Sirva como muestra lo que se señala desde el Fanzine Colectivx, Cuerpxs menstruantes: "cada mujer tiene su forma constitucional de menstruar, si sale de los límites considerados como "normales" no necesariamente es que tiene alguna patología" (2015, p. 21), desde donde se denuncia, también, el potente vínculo entre normalidad y patología que articula la regulación bio-médica de estos cuerpos.

Por otro lado, al hundir sus raíces en las memorias ancestrales de cada región, estas propuestas generan un tipo de conocimiento entre la tradición y la modernidad, en el que no solo son fundamentales las experiencias geo-históricas, sino la memoria colectiva de una herida colonial que comienza con la caza de brujas de los siglos XVI y XVII, continúa con la colonización de los territorios de Abya Yala y sigue produciéndose en la actualidad con las distintas manifestaciones de violencia hacia los cuerpos femeninos o feminizados (Silvia FEDERICI, 2015).

Por eso, entre sus objetivos están, por un lado, la recuperación de narrativas más positivas en torno a la vivencia de la menstruación, aunque a veces ello estanque su discurso en una suerte de esencialismo genérico. Por el otro, la promoción de prácticas de autoconocimiento y de autogestión de la salud que implican una relación amorosa y de cuidado con respecto al cuerpo y al medio ambiente.

Conviene aclarar que entiendo la GN como un ejemplo de lo que Walter Mignolo denominó una "[...] oposición desplazada" (MIGNOLO, 2007, p. 33) respecto al pensamiento único, es decir, como una forma de resistencia que crea alternativas de racionalidad ética en la que se recuperan valores tradicionalmente producidos como intangibles (amor, cuidado, ecología, por ejemplo), al mismo tiempo que genera diálogos conflictivos con respecto a las condiciones neoliberales de existencia.

Es fundamental comprender, en este sentido, cómo el repertorio de afectos y emociones que se actualizan con algunas de las propuestas de la GN enriquecen y problematizan las dinámicas

${ }^{3}$ Por "occidentalizadas" me refiero a aquellas culturas que han experimentado un proceso de transculturación -por efecto de la colonialidad o de la fuerte inmigración- en el que diversos aspectos culturales se mezclan de manera indiferenciada, en vez de coexistir y convivir como sucede en ciertas sociedades multiculturales. 
de subjetificación propias del liberalismo avanzado actual (Nikolas ROSE, 1996, p. 37-64), en las que no hay una exterioridad que discipline, sino que son los propios sujetos quienes se sujetan a las prácticas de vida que eligen (ROSE, 2003, p. 215).

La insistencia de muchos de los manuales y fanzines en incentivar la autogestión de la salud menstrual, con prácticas que reivindican el autoconocimiento de todas las partes del aparato reproductor (PÉREZ SAN MARTíN, 2015, p. 65-89) o con explicaciones que enseñan a confeccionar de manera personalizada el material de higiene bajo la premisa de un empoderamiento, pueden leerse a la luz de esta última cuestión. Pero siempre teniendo bien presente que los proyectos decoloniales también son constitutivos de la modernidad, es decir, se gestan y se desarrollan, así sea de manera subalterna / subversiva, en la matriz colonial de poder (MIGNOLO, 2007, p. 26), por lo que se hace necesario siempre abordarlos desde una perspectiva abierta y crítica.

Partiendo de aquí, en los siguientes apartados se explorarán aquellos elementos que considero constitutivos de la GN, a saber: la apertura hacia formas otras de nombrar-se y de nombrar el cuerpo, con un lenguaje mucho más metafórico y reivindicativo; la recuperación de un saber "femenino" que ha sido invisibilizado, negado y estigmatizado; y una visión integral de la salud que procura un cuerpo activo por medio del compromiso con una alimentación sana, con la práctica de ejercicios físicos (básicamente, el Yoga), y con un conocimiento básico y general de herbolaria.

\section{Redefiniendo conceptos y realidades}

Eugenia Tarzibachi afirma en su reciente estudio que "[u]no de los desafíos que tenemos que enfrentar es producir nuevas narrativas sobre la menstruación para las nuevas generaciones de mujeres y varones" (TARZIBACHI, 2017, p. 111). También Walter Mignolo señala que una de las causas principales de que los movimientos de descolonización fracasaran fue que cambiaron el contenido, pero no la forma: "El límite de todos estos movimientos fue no haber encontrado la apertura y la libertad de un pensamiento-otro, esto es, de una descolonización que llevara, en términos de los zapatistas, a un mundo en donde cupieran muchos mundos (la pluriversalidad)" (MIGNOLO, 2007, p. 31).

Los límites del lenguaje son los límites de nuestro mundo. Por eso mismo, estas propuestas exploran posibilidades de apertura y desprendimiento desde el lenguaje para, desde las mismas, otear formas de apertura y desprendimiento de la realidad. Por ejemplo, Pabla Pérez San Martín titula el tercer capítulo de su manual "Descolonizar nuestro cuerpo" (PÉREZ SAN MARTíN, 2015, p. 4563), y lo acompaña de un sucinto recorrido por aquellos genitales y órganos reproductores de un cuerpo heteronormativamente marcado como femenino.

Lo particular, en su caso, es, por un lado, que cada una de estas partes recibe, junto a su nomenclatura más común, una más poética; por otro lado, que cada ítem tiene al lado su correspondiente dibujo ilustrativo; y, por último, el detallismo en la exploración de aquellas partes del cuerpo externas e internas, nombrando incluso las que no son de uso tan habitual.

Así pues, el vello púbico se convierte en "Musgo Fragante", la vulva en "Mar de Conocimientos", el monte de Venus en "Montaña Adorable", los labios (mayores y menores) en "Medias Lunas", el clítoris en "Fuente de Placer", el vestíbulo vulvar en "Patio Celestial", la vejiga en "Cántaro Áureo", el periné (suelo pélvico) en "Puente de Poder", la vagina en "Camino a la Fuente", el himen en "Capullo de Flor", el cérvix o cuello del útero en "Puerta de la Fuente", el moco cervical en "Guardián Protector", el os (orificio cervical interno y externo) en "Pasaje Luminoso", la útera en "Espacio Sagrado / Fuente / Matriz", el endometrio en "Reboso Carmesí", las trompas uterinas en "Caminos Serpenteantes", los ovarios en "Nidos de Perlas", los ovocitos (óvulos) en "Semillas de Creación y Renovación" y las glándulas vulvovaginales en "Néctar de Placer".

Estos modismos, a pesar de que siguen reproduciendo una actitud de disimulo lingüístico con relación al proceso corporal de la menstruación, apuntan, sin embargo, a una resignificación positiva del mismo dentro del orden sociocultural. Destaco la repetición de palabras como "fuente" o "placer", ya que transforman la vivencia abyecta, asquerosa y vergonzante de un cuerpo menstruante en una vivencia placentera, gozosa y cíclica. También el cambio en la morfología de la palabra "útera" y en la expresión "Trompas uterinas", puesto que, si el lenguaje tiene sus límites, también los impone: lo que se calla, no existe, y eso implica asumir que solo existe una realidad, la masculina, que además se impone sobre la otra, la femenina.

Recuperar la " $a$ " o la " $x$ " en este contexto específico y en otros más generales (como cuando se habla de "cuerpa" o de "cuerpx"; FANZINE COLECTIVX, 2015), tiene que ver con la necesidad de visibilizar experiencias y voces otras, mucho más plurales y corales, en torno a la menstruación, a las representaciones corporales y, por supuesto, a las identidades. A su vez, el cambio del significante Fallopio, apellido del "descubridor" de estas partes del cuerpo, por "uterinas" obedece a lo contrario, esto es, a la voluntad de tachar una fuerte colonización masculina y bio-médica para reescribir sobre ella la huella de una decolonialidad corporal y territorial. Quizá ello se comprenda mejor con el ejemplo que aportan desde el anteriormente citado Fanzine colectivx: 
COLONIZACIÓN CORPORAL.

*Fallopio, Sims, Skene, Bartolino... "ídolos de la ginecología" cuyos apellidos fueron cínicamente utilizados para nombrar partes de nuestro cuerpo. Todos ellos fueron sádicos que practicaron la vivisección humana, sin anestesia a esclavas anónimas, o inmigrantes pobres, quienes escribieron la historia de la ginecología con sus cuerpos.

Invocamos renombrar las partes de nuestros cuerpos para desterrar la ocupación colonial que nos habita. En el caso de las trompas de Fallopio, las llamamos por su verdadero nombre, Trompas Uterinas. (FANZINE COLECTIVX, 2015, p. 13. La itálica es mía, la negrita de ellxs)

No debe sorprendernos el uso del símil bélico porque, más allá de las metáforas poéticas con las que se manejan en el ámbito de la GN, muchas de estas propuestas se inscriben conscientemente en un contexto de fuertes disputas por los cuerpos y las corporalidades, entendidas como territorios usurpados/colonizados. En esta línea, se habla de la "útera" como una forma de devolverle la autoridad del saber sobre sus cuerpos a todas las bio-mujeres que lo han ido perdiendo desde la imposición del modelo capitalista y el encumbramiento de la Medicina como saber único y legítimo.

Un manual de reciente aparición como es el Manual de Ginecologia Natural \& Autônoma plantea que "este manual também pode ser utilizado por mulheres que não menstruam, mulheres trans, mulheres que usam anticoncepcional e até mesmo homens" (SOUZA et al., 2017, p. 8), abriendo el abanico de lectores/as a las infinitas realidades que atraviesan y son atravesadas por la menstruación.

Del mismo modo, el Fanzine colectivx habla de "cuerpxs" como una forma de desplazarse de un sistema de pensamiento sexo-genérico que quiere cuerpos heteronormativamente marcados por tecnologías varias, entre ellas, las de género, y que, por eso mismo, relega la menstruación al saco de las "cosas de mujeres". El hecho de que acompañen esta decisión lingüística con dibujos que muestran corporalidades fuera de la norma, con las piernas y las axilas sin depilar o con abundancia de carnes, por ejemplo, es también una forma de romper con muchos de los estereotipos que acompañan el "ser mujer" y el "tener cuerpo de mujer" según la heteronorma.

En este sentido, quiero hacer un breve inciso. En los últimos cuatro años han empezado a circular en espacios alternativos una serie de libros destinados al público más joven. Se trata de propuestas literarias en las que, por medio de una interesante combinación entre narrativa e imágenes, se quiere presentar positivamente la menstruación a quienes están por vivenciarla por primera vez. En todas ellas llama la atención esta feminización de los cuerpos menstruantes.

Así, por ejemplo, en Las lunas, un mini-manual ginecológico de Victoria de Aboitz, nos encontramos con un capítulo titulado "De niña a mujer", en el que resalta esta idea: "ESTÁS RECIBIENDO EL REGALO Y LA RESPONSABILIDAD DE SER MUJER" (2014, p. 15; en mayúscula en el original). Mi primer libro Rojo, de Violeta Del Río está dedicado a "[...] todas las niñas que están despertando a su Mujer", hasta el punto de reproducir ciertos estereotipos, como cuando Ana, la protagonista, le pregunta a su madre: “¿Qué? ¿Señorita?”, y ésta le responde: “Sí, mi amor, te hiciste mujer" (2016, s.p.). También Mamá me vino... de May, Marta y Julia Serrano (2015) se presenta en su contratapa como "[...] un cuento para, entre madres e hijas, poder explicar y explicarse que supone la llegada de la menstruación en el tránsito entre niña y mujer".

Esta concepción esencialista de la menstruación, en la que se grava con insistencia el vínculo entre la condición femenina y la materialidad de los cuerpos sexuados es, quizá, el rasgo más definitorio de estas propuestas, aunque los ejemplos anteriormente mencionados de Souza et al. y del Fanzine colectivx permiten entrever aires de cambio. Más allá de que se acuerde o no con esta lógica, lo cierto es que, hoy por hoy, me parece sumamente interesante releerla como estrategia de reescritura de las pautas neoliberales de subjetivación y de gestión de las corporalidades. Y no tanto por esta ficcionalidad que significa el "ser mujer" a través de la vivencia del sangrado menstrual, sino por las experiencias comunitarias y amorosas que reivindican, y que les permiten afianzar una idea de unidad, de urdimbre entre todas las mujeres que conformarían el llamado ginecogrupo por ciertas autoras de referencia (Casilda RODRIGÁÑEZ BUSTOS, 2009, p. 71-93).

El hecho, entonces, de que se sigan excluyendo otras vivencias en estos contextos de literatura infanto-juvenil y en los manuales puede ser interpretado desde este supuesto: hay una necesidad inmediata de construir un nuevo orden de género basado en la experiencia de grupo y de afectos/emociones/territorialidades compartidas para, desde ahí, abrirse al acompañamiento de otras tantas realidades igualmente excluidas, sometidas y subalternizadas por el conocimiento/ poder único y hegemónico.

\section{De saberes y haceres}

Creo que abrazar mi menstruación fue una invitación a abrazarme tal cual soy y rotundamente soltar la creencia que éste sistema me enseñó: que en mí, por nacer con matriz, ya había algo malo, sucio, molesto, que debía ocultar. Y que sólo era importante si deseaba ser madre

${ }^{4}$ La negrita aparece en rojo en el original. 
después. Por eso minimicé mi salud y tomé anticonceptivos por varios años. Hoy sé que la menstruación es poderosa en sí misma. Que es antripatriarcal por excelencia, genuinamente. Que en un sistema antivida, de muerte como éste jamás son nuestros cuerpos los que están mal. Mi sangre me enseña sobre la dignidad de vivir. Sobre el silencio, el enojo, andar oscura, decir verdades, descansar, decir basta. Y fue la llave para reconocer el poder increíble de la Regeneración. Algo que la Naturaleza cuenta, y que es información disponible para cualquier ser que desee escuchar. Poder de Regeneración. Puedo ser lo que deseo ser, no lo que me dijeron, lo que me dije o lo que creí que era. Mi existencia como expresión máxima de mi creatividad. (Maja CORREA POUSA, fundadora de Sanación Matriz5)

Si ahora profundizamos en las narrativas que se comparten desde la GN, podemos observar que se construyen en torno a una serie de ideas o preceptos, de los que destaco los siguientes: una autogestión de la salud que implica, entre otras cosas, una responsabilidad en el autoconocimiento, el autocuidado y el cuidado del entorno; un empoderamiento a través del reconocimiento y la validación de las experiencias de transformación del ciclo menstrual; y la vivencia de un gozo corporal. Todo ello acompañado por la idea de recuperación, de reapropiación de algo (el saber, sobre todo) que se considera usurpado por la bio-medicina y por su mirada masculina/ masculinizada.

Cabe destacar el carácter informativo que tienen estas propuestas, cuyo objetivo general es ofrecer acceso libre al conocimiento del cuerpo, de sus particularidades y, en última instancia, de la identidad. Se resalta la importancia de que las mujeres se sientan y se sepan capaces de conocerse interna y externamente (se empoderen) y que, precisamente por ello, se sepan aptas para no delegar ningún saber ni ningún hacer a otra persona (el/la médico/a) ni a otra institución (la bio-medicina) que no sea la que constituye su propio cuerpo. Léanse, como ejemplo, estas palabras de Liliana Pogliani, quien responde así a la pregunta "¿De qué trata la Ginecología Natural?":

Para hablar de ginecología natural tendríamos que comenzar por el maravilloso mundo del auto-conocimiento femenino, algo que socialmente no está muy difundido en nuestros tiempos (porque no nos lo enseñaron nuestras madres, ni lo aprendimos en la escuela) pero, el cual es indispensable para abordar una ginecología consciente, la que nos conducirá indefectiblemente al empoderamiento femenino. (POGLIANI, s.a., p. 7; las itálicas son mías, la negrita es de la autora)

Desde mi perspectiva, y a pesar de que pongo en duda la etiqueta de "femenino" en la aplicación de estos saberes, la mención al "maravilloso mundo del auto-conocimiento", así como a una "ginecología consciente" confiere a esta y a las demás propuestas mencionadas un valor contracultural de sumo interés, fundamentado precisamente en la revalorización de bienes producidos como intangibles por el sistema-mundo actual: gratuidad, vitalidad, sustentabilidad.

Los conceptos que se manejan generan un polimorfismo cognitivo dentro del movimiento, creando sentidos plurales sobre las dimensiones reales y no ficcionales de los cuerpos, en especial de los cuerpos femeninos y feminizados.

La menstruación, en estos discursos, se convierte entonces en aquello que nuclea los momentos de apertura y de desprendimiento en el proceso de descolonizar el cuerpo, el ser y el saber, hasta el punto de que el ciclo menstrual se convierte en el medio para comenzar el camino del autodescubrimiento, del autoconocimiento y / o de la auto-profundización acerca de la identidad propia.

La cita que encabeza este apartado da buena cuenta de esta idea: la interlocutora habla de "abrazar" la menstruación como instancia previa para "abrazarse" a sí misma. Para ello, apela a una serie de importantes desplazamientos en la narrativa menstrual: de una significación meramente productiva y mercantil del verbo "poder" a una más bien esotérica, conectada con la Naturaleza (en un sentido arquetípico del término) y con sus manifestaciones; de las imposiciones del "mandato" social, cultural y familiar a la vivencia de un "deseo" en primera persona; de la reducción del cuerpo menstrual a cuerpo materno o reproductivo a su goce por el simple hecho de ser, de sentir y de verse atravesado por todos estos procesos.

Este lugar central de la menstruación en la producción de estas discursividades es lo que explica, por un lado, que se hayan ampliado los límites del propio término: menstruar ya no es solo "evacuar el menstruo", como reza la definición online del DRAE, sino ciclar, atravesar mes a mes distintos estados, entre ellos, el sangrado. Por otro lado, que se redefinan también los límites del contexto menstrual: del mismo modo que ya no es solo la sangre, tampoco es solo el útero y los llamados órganos reproductores. Es eso y mucho más: es exploración interna, es sabiduría externa, es sexualidad, es cuidado y es salud.

Por eso mismo también, la GN debe entenderse como una interesante y compleja cruza de saberes, de los que aquí destaco dos.

\footnotetext{
${ }^{5}$ En mensaje personal a la autora, https://www.facebook.com/sanacionmatrizMaja/, en marzo de 2018.
} 
En el primero de ellos, la menstruación es celebrada como un momento de gran conexión con el "femenino arquetípico" 0 con la "sabiduría de mujer" (Christiane NORTHRUP, 2010, p. 156159), con los ciclos de la naturaleza (en especial, las estaciones) y, sobre todo, con los ciclos lunares. En palabras de Pabla Pérez San Martín: "Vamos fluctuando como las mareas, las estaciones del año, las plantas y los movimientos de la luna" (PÉREZ SAN MARTíN, 2015, p. 148; el itálico es mío). Conocer e integrar esta ciclicidad deviene el punto de partida para conocerse e integrar no solo aquellos aspectos positivos de la personalidad, sino también, y muy especialmente, los negativos, aquello que Maja Correa Pousa expresa con sus palabras: "silencio, el enojo, andar oscura, decir verdades, descansar, decir basta"?.

Es muy importante tener en cuenta esta cuestión, ya que es un indicativo de la torsión que estas discursividades pretenden promover respecto a ciertas lógicas capitalistas. El peso que se le da a este aspecto oscuro del ser, cuyo reflejo es la oscuridad de la luna cuando está en Luna Roja o en luna nueva, puede interpretarse, por un lado, como una contra-lectura a la idea del cuerpo hiperproductivo todos los días del año; y, por el otro, como la reapropiación de una de las derivas más problemáticas de la bio-medicina con respecto a los posibles desajustes que pueden darse a lo largo del ciclo.

Me refiero aquí al llamado Síndrome Premenstrual (SPM), producido como un causal de la incapacidad de la mujer para gestionar y realizar sus tareas fuera del ámbito doméstico y, por eso mismo, esgrimido como argumento lícito para expulsar a la mujer del mundo laboral o, actualmente, para limitarle los accesos en igualdad de condiciones (FELITTI, 2016, p. 181 y 184). Frases como "No le temas a la mujer premenstrual que eres", "iEs poderosa! Altamente creativa e imponente" o "te conecta con tu naturaleza salvaje femenina" (FANZINE COLECTIVX, 2015, p. 23; las itálicas son mías), si bien no están exentas de cierto tono imperativo, resumen este viraje hacia la resignificación positiva de una etapa del ciclo que presenta ciertas particularidades (cambios de humor y físicos, sobre todo), y que el discurso bio-médico ha sabido aprovechar y utilizar privilegiadamente.

Miranda Gray (s.a.) o Jean Shinoda Bolen (2001) son, respecto a esta primera narrativa, los referentes más citados y reproducidos, si bien, como ya señalé en párrafos anteriores, su mirada se entreteje con una memoria local y colectiva, recopilada en muchos casos a través del contacto con otras realidades más o menos cercanas. Victoria de Aboitz añade un apartado titulado "La menstruación en diferentes culturas", escrito por Sophia Style ${ }^{8}$, en el que se recogen los casos de cuatro lugares bien alejados del mundo donde la menstruación es enaltecida y ritualizada. Reproduzco los títulos para dar cuenta de qué tipo de ejemplos se utilizan -culturas muy ligadas a lo ancestral y a lo espiritual- para explicar el ritual de la menstruación: "Imagina que eres una niña apache", "Ahora vamos a la tribu Aiary, en Brasil", "Continuamos nuestro viaje, cruzando el Océano Atlántico" y "Ahora cruzamos el Océano Índico y acabamos nuestro recorrido en Sri Lanka" (ABOITZ, 2014, p. 33-35).

También el Manual introductorio a la Ginecología Natural presenta los cuatro ciclos del diagrama lunar que aparece en Luna Roja (GRAY, s.a., p. 165) en diálogo con la cosmovisión del pueblo mapuche. Un repaso rápido por el capítulo de su libro titulado "Ciclo menstrual" nos muestra cómo el saber se construye como un pluriverso en el que tienen cabida lenguas, memorias, mitos y conocimientos de muy diversa índole. Así, el "ciclo menstrual" se convierte en "energía cíclica" y en Küyentún, es decir, en el movimiento constante de la luna según la lengua mapundungun. Cada una de las cuatro etapas de este ciclo (la menstrual, la pre-ovulatoria, la ovulatoria y la pre-menstrual) es ampliamente abordada a través de una serie de prescripciones cuyo objetivo es facilitar una mejor comprensión, acompañamiento e integración de las mismas.

El esquema se repite en cada fase: una definición fisiológica, el arquetipo que le corresponde según la mirada mapuche y según la propuesta de Gray, la estación del año y el movimiento de la luna con la que se identifica, las distintas diosas (de origen sumerio, griego, romano, mapuche u orixá) que la representan, las plantas -principalmente autóctonas- que ayudan a transitar los desórdenes que la pueden afectar, recomendaciones alimentarias y, finalmente, algunos ejercicios que pueden llevarse a cabo para una mejor integración de la emoción despertada en este momento del ciclo y su manifestación corporal: Yoga es el que más se repite, pero también aparecen el Taichi o las danzas del vientre.

Junto a la transmisión de estos saberes, Pérez San Martín añade algunas prácticas concretas para vincularse de otra forma con la sangre menstrual: venerarla a través del arte, de la creación de un altar, de la desconexión con la tecnología y la reconexión con la Naturaleza (PÉREZ SAN MARTíN, 2015, p. 144-146); reciclarla para uso medicinal (PÉREZ SAN MARTíN, 2015, p. 147-148) o ritualizarla. Del mismo modo que Victoria de Aboitz habla de culturas de distintas partes del mundo en las que la menstruación es celebrada, la chilena reivindica el saber de "[...] diversas culturas

${ }^{6}$ Esta expresión la saqué de un manual de ginecología natural publicado como un pequeño libro de 7x14, y puesto en circulación por Flor de Luna en Córdoba. Es probable que hoy en día su acceso sea más limitado.

${ }^{7}$ Mensaje personal a la autora, https://www.facebook.com/sanacionmatrizMaja/, en marzo de 2018.

${ }^{8}$ Creadora e impulsora de Mujer Cíclica, cuyo subtítulo no puede ser más significativo: "Conecta con tu sabiduría femenina". 
y tribus con enfoques matriarcales" que "a través de un bello ritual celebran la bendición de la llegada de la fertilidad en las niñas" (PÉREZ SAN MARTíN, 2015, p. 141; los itálicos son míos). De esta manera, se sigue insistiendo en la idea de pertenencia a un grupo: las "niñas" devienen "mujeres" por medio tanto de la menstruación como de los conocimientos que les son transmitidos de boca en boca, generacional y comunalmente.

Por otro lado, la mención a un enfoque matriarcal, por oposición al enfoque patriarcal que, según la autora, explicaría que en otras partes del planeta, en esa transición del ser "niña" al "ser mujer", las niñas sean sometidas a prácticas de una violencia extrema, como pueden ser permanecer encerradas y alejadas de la comunidad durante el período del sangrado o sufrir la mutilación genital, seguiría ahondando en esta brecha entre modos, saberes y haceres "masculinizados" y "feminizados". Si bien estratégicamente me parece válido para confirmar este nuevo orden de género en el que el colectivo mujeres tendría mucho que aportar, debe siempre tomarse con precaución, porque si no, se corre el riesgo de caer una vez más en un esencialismo excluyente y generalizador.

Por lo que respecta a la vinculación que realiza entre la menstruación y la fertilidad de los cuerpos, nos puede servir para introducir el segundo de los saberes que mencioné al comienzo de este apartado, al que podemos etiquetar como un saber científico. Este apela a las variaciones hormonales ${ }^{9}$ f fisiológicas que se producen a lo largo del ciclo, y que comprometen a dos órganos al completo: de un lado, al útero junto con los ovarios, las trompas, el endometrio, el cuello y el moco cervical; $y$, del otro, al cerebro, junto con los neurotransmisores, las endorfinas, el hipotálamo y la glándula pituitaria.

Recuerda Tarzibachi que lo común en los textos científicos que abordan la menstruación es que los órganos reproductivos "femeninos" y "masculinos" sean tratados en un orden jerárquico: el útero es el que produce los óvulos para que el espermatozoide los fecunde, orientándose todo única y exclusivamente a la reproducción (TARZIBACHI, 2017, p. 42).

Con esta retórica dialogan estos manuales cuando refieren al "Período fértil (fase ovular)" (SOUZA et al., 2017, p. 19) y narran de distintas maneras el breve instante (de veinticuatro a cuarenta y ocho horas) en el que el óvulo se desprende del ovario e inicia su camino hacia una posible fecundación: "si no es fecundado, muere en la trompa uterina" (PÉREZ SAN MARTíN, 2015, p. 161; el itálico es mío), "De no ser fecundado el óvulo se desintegra y es eliminado con otras secreciones vaginales generalmente días antes del sangrado menstrual” (FANZINE COLECTIVX, 2015, p. 12; también ahora el itálico es mío).

Destaca la alusión a un elemento del cuerpo que muere o se desintegra, ya que conecta con la idea de que la menstruación es buena porque ayuda a eliminar del cuerpo aquello que ya no sirve. En las palabras del Fanzine Colectivx: "nuestra limpieza biológica natural va acompañada también de una limpieza psíquica" (FANZINE COLECTIVX, 2015, p. 13).

Por otro lado, este suele ser también el punto de partida para plantear formas de autoconocimiento y de autogestión de la salud de los cuerpos. Se trata de formas que implican una observación y un contacto directo con el cuerpo: ya sea para reconocer las distintas metamorfosis del moco cervical a lo largo del ciclo, ya para explorarse detenidamente los pechos, ya para identificar algún desorden en el cuello del útero, principal foco de infecciones y enfermedades más o menos graves (en especial, el HPV). El espéculo es el elemento por excelencia, recomendado como herramienta básica de una ginecología consciente, natural y autogestiva, e incluso algunos manuales como el de la Dra. Liliana Pogliani enseñan a medir el pH vaginal por medio de una tira reactiva que, al igual que el espéculo, es de fácil acceso en farmacias (POGLIANI, s.a., p. 27-31).

Todo ello se acompaña de un cuestionamiento de los dispositivos de regulación que impone la bio-medicina (los distintos anticonceptivos que ofrece el mercado, desde las pastillas hasta los implantes subcutáneos o los DIU; pero también la detención temporal del sangrado), y de una apertura con respecto del pensamiento único que concibe el cuidado de la salud sexual como tema exclusivamente femenino y con una sola finalidad, la procreación. Me parecen, entonces, interesantes reflexiones como la que se encuentran en el Manual de ginecología Natural \& Autônoma:

É importante desmitificar a ideia de que só sentimos nossa líbido alta no período ovular. Isso é fruto de um pensamento que estabelece para as mulheres apenas a função procriatória. Mas não é bem assim, pois temos un orgão destinado exclusivamente ao prazer: o clitóris. Mulheres estéreis, hiterectomizadas, crianças e pós-menopáusicas continuam com suas funções clitorianas independentes e atuantes. A reprodução é uma função secundária e opcional da nossa sexualidade. O prazer, função mais importante, melhora nossa conexão com nós mesmas. (SOUZA et al., 2017, p. 19-20)

'El manual de Pérez San Martín, de hecho, tiene un capítulo entero dedicado a las hormonas, definidas como "Nuestras mensajeras de energía" (PÉREZ SAN MARTíN, 2015, pp. 179-191). Sin embargo, lo más común es que se mencionen las que cito a continuación en el cuerpo del texto. 
La función reproductiva se desplaza de su lugar de privilegio y, en su lugar, se colocan el placer corporal y uno de los órganos que lo hacen posible: el clítoris. Se trata del órgano más visible y con el que más fácilmente se identifica el placer sexual de un cuerpo marcado como femenino, aunque no es el único, tal y como se viene visibilizando desde estas instancias. Por ejemplo, el proyecto autogestivo Anarchagland propone renombrar dos de las glándulas implicadas en la lubricación (Bartolino) y la llamada eyaculación femenina (Skene) a partir de un trabajo de recuperación histórico de esas voces y esos cuerpos silenciados y usados como material de pruebas por parte de los primeros investigadores modernos en ginecología. Según esto, a las primeras les correspondería el nombre de Anarcha y a las segundas el de Lucy y Betsy, tres mujeres esclavas de América del Norte ${ }^{10}$.

En definitiva, todas estas acciones van propiciando que nuevos sentidos se vayan sumando a los persistentemente transmitidos por la bio-medicina o la industria de la higiene femenina y que, de manera sutil, los vayan presionando, cuestionando y erradicando de algunos imaginarios personales y colectivos.

\section{Palabras finales}

La propuesta de este artículo fue ofrecer una lectura decolonial de algunos ejemplos escritos de la GN que circulan en los territorios de Abya Yala.

En función de ello, se seleccionaron una serie de manuales (para jóvenes y adultas) que vienen circulando fuera del mercado editorial mainstream, ya sea con propuestas como la de financiamiento crowdfunding (el Manual introductorio a la Ginecología Natural de Pabla Pérez San Martín), ya sea con autoediciones (el libro Ginecología Natural al alcance de Todas. Autoconocimiento femenino y medicina natural, de la Dra. Liliana Pogliani), ya sea con ediciones on-line de libre y globalizado acceso (el Fanzine colectivx Cuerpxs menstruantes; o el Manual de Ginecologia Natural \& Autônoma, de Lais Souza y otras).

En todas ellas pude advertir distintas narrativas con relación a cómo las mujeres deben vivenciar o atravesar mensualmente sus menstruaciones. En esta línea, tuve que reconocer un discurso hegemónico que procura inscribir en la niña devenida en mujer menstruante una serie de dispositivos de gestión, de ocultación y de higiene que la confinan a un conjunto de tareas -domésticas, corporales y de responsabilidad en el autocuidado-, cuya dedicación de tiempo tensiona la posibilidad de que este nuevo sujeto se proyecte en la esfera de lo público, lo político o lo laboral.

Un primer análisis permitió constatar el interés que los proyectos de GN tienen a la hora de redefinir, desde el lenguaje y desde sus significaciones, la menstruación, entendida ya como un ciclo del que es necesario ir reconociendo cada una de sus partes para comprender el todo.

También quedó manifiesta la importancia que en todos estos discursos tiene el cuerpo. Éste es entendido como una territorialidad que debe ser re-apropiada y des-colonizada tanto por el lenguaje que lo nombra y lo encorseta, como por quienes lo habitan y lo sienten. De ahí que en algunos ejemplos cercanos en el tiempo (FANZINE COLECTIVX, 2015; SOUZA et al., 2017) se utilice un lenguaje más inclusivo de todas las realidades y que se insista, también, en comprender el ciclo menstrual como una etapa más de la sexualidad humana. La recuperación de una narrativa como la del placer corporal -semantizada en el clítoris y en las glándulas de Anarcha, Betsy y Lucy $^{11}$ - avanzaría en esta dirección.

Ahora bien, si algo se ha podido comprobar es que en la mayoría de los ejemplos aportados el ciclo menstrual sigue estando profundamente atravesado por tecnologías de género que reproducen binarismos en materia subjetiva. Así, narrativas como "hacerse señorita" se entrelazan con las del empoderamiento femenino. Esto ha sido interpretado como una forma de afianzar un nuevo orden de género en el que la figura mujer crearía una red de sentidos diferente, desde la que sería posible imaginar modos otros de vinculación y de hacer política (SEGATO, 2016, p. 106).

No obstante, no puedo dejar de señalar el hecho de que estas lógicas siguen obliterando la posibilidad de imaginar tantas otras realidades en la experiencia corporal de la menstruación.

En mis incipientes exploraciones de campo, me encontré con personas que sienten la necesidad de extirparse directamente el útero. La explicación primera es que no pueden ni quieren seguir lidiando con ciertos desajustes hormonales y corporales (cambios bruscos de humor, sudoraciones extremas, dolor pélvico agudo), pero al ahondar en su decisión fue posible descubrir una necesidad de desidentificarse de la asociación menstruación-femineidad y de desplazarse de algunos de los modelos de mundo que en torno a ella se construyen, como pueden ser, por ejemplo, esta pertenencia al grupo mujeres o el reclamo de cierto privilegio por el hecho de menstruar.

No desatender estas realidades se hace necesario para poder abordar en toda su complejidad un movimiento como el de la GN, que presenta propuestas de transformación sociocultural muy interesantes, tanto en lo que refiere a la resignificación en positivo de un fluido

\footnotetext{
10 https://anarchagland.hotglue.me/?anarcha_lucy_betsey. Acceso el 08/04/2018.

${ }^{11}$ https://anarchagland.hotglue.me/?anarcha_lucy_betsey. Acceso el 08/04/2018.
} 
corporal específico, la sangre menstrual, como en lo que respecta a la problematización de ciertos procesos de subjetivación propios de las sociedades neoliberales contemporáneas.

El que ha requerido mi atención en estas páginas ha sido el que se encuentra atravesado por las tecnologías de género, de las cuales estos manuales y fanzines no están exentos. Sin embargo, también se ha podido constatar, aunque de manera epidérmica, cómo los ejemplos aquí trabajados se ven de igual forma atravesados por tecnologías del yo que promueven lógicas de autocuidado, autoconocimiento y autogestión de la salud. Lógicas como la del "empoderamiento femenino", por ejemplo, pueden verse reducidas a las capacidades de responsabilidad y resolución subjetivas si no se abordan de manera abierta, plural y en tensión permanente con aquello mismo contra lo que pretenden alzar su mirada y sus voces descolonizadoras. Queda, pues, para análisis futuros, encarar esta cuestión e ir desenmarañando la tupida red en la que estas propuestas descolonizadoras tejen y articulan sus resistencias dentro de la modernidad / contemporaneidad.

\section{Referencias bibliográficas}

ABOITZ, Victoria de. Las lunas. Las Chacras: la autora, 2014.

BOBEL, Chris. New blood. Third wave feminism and the politics of menstruation. London: Rutgers University Press, 2010.

BOSTON WOMEN'S HEALTH COLLECTIVE. Our Bodies, Ourselves. A book by and for Women [online]. Boston, 1970. Disponible en https://www.ourbodiesourselves.org/history/reading-our-bodies-ourselves/ . Acceso 02/03/2018.

DEL RíO, Violeta. Mi primer libro Rojo. Buenos Aires: la autora, 2016.

FANZINE COLECTIVX. Cuerpxs menstruantes. Lima: Hazlo Pirata, 2015.

FEDERICI, Silvia. Calibán y la bruja. Mujeres, cuerpo y acumulación originaria. Buenos Aires: Tinta Limón, 2015.

FELITTI, Karina. "El ciclo menstrual en el siglo XXI. Entre el mercado, la ecología y el poder femenino". Sexualidad, Salud y Sociedad- Revista Latinoamericana [online]. Rio de Janeiro, 2016, n. 22, p. 175-206. Disponible en http://www.scielo.br/scielo.php?pid=\$1984-64872016000100175\&script= sci_abstract\&tIng=es. ISSN: 1984-6487. Doi: 10.1590/1984-6487.sess.2016.22.08.a. Acceso 20/02/ $20 \overline{1} 8$.

GRAY, Miranda. Luna Roja. Córdoba: Flor de Luna, 1994.

IRUSTA, Erika. "Proyecto soy1 soy4". España. Disponible en https://soy1 soy4.com/sobre-este-proyecto/ . Acceso 20/12/2017.

KLIMOVSKY, Gregorio. Las desventuras del conocimiento científico. Una introducción a la epistemología. Buenos Aires: A-Z editora, 1997.

MIGNOLO, Walter. "El pensamiento decolonial: desprendimiento y apertura. Un manifiesto". In: CASTRO GÓMEZ, Santiago; GROSFOGUEL, Ramón (Eds.). El giro decolonial. Reflexiones para una diversidad epistémica más allá del capitalismo global. Bogotá: Siglo del hombre Editores; Universidad Central, Instituto de Estudios Sociales Contemporáneos y Pontificia Universidad Javeriana, Instituto Pensar, 2007. p. 25-46.

NORTHRUP, Christiane. Cuerpo de mujer, sabiduría de mujer. Una guía para la salud física y emocional. Barcelona: Urano, 2010.

PÉREZ SAN MARTíN, Pabla. Ginecosofía. Sabiduría ancestral de las mujeres, Chile, 2009. Disponible en https://ginecologianatural.wordpress.com/. Acceso 01/04/2018.

PÉREZ SAN MARTíN, Pabla. Manual introductorio a la Ginecología Natural. CABA: Melisa Wortman Moreno, 2015.

PÉREZ SAN MARTíN, Pabla; CHEUQUELAF, Inés; CERPA, Carla. Del cuerpo a las raíces. Uso de plantas medicinales para la salud sexual y reproductiva de las mujeres. CABA: Ginecosofía, 2017.

POGLIANI, Liliana. Ginecología Natural al alcance de Todas. Autoconocimiento femenino y medicina natural. Argentina: la autora, s.a. 
ROSE, Nikolas. "Governing 'advanced' liberal democracies". In: BARRY, Andrew; OSBORNE, Thomas; ROSE, Nikolas (Eds.). Foucault and Political Reason. Liberalism, neo-liberalism and rationalities of government. Chicago: The University of Chicago Press, 1996.

ROSE, Nikolas. "Identidad, genealogía e historia". In: HALL, Stuart; DU GAY, Paul (Eds.). Cuestiones de identidad cultural. Buenos Aires: Amorrortu, 2003.

SANYAL, Mithu M. Vulva. La revelación del sexo invisible. Barcelona: Anagrama, 2012.

SEGATO, Rita Laura. Las nuevas formas de la guerra y el cuerpo de las mujeres. Madrid: Traficantes de Sueños, 2014.

SEGATO, Rita Laura. La guerra contra las mujeres. Madrid: Traficantes de Sueños, 2016.

SERRANO, May; SERRANO, Marta; SERRANO, Julia. Mamá me vino... CABA: Madreselva, 2015.

SHINODA BOLEN, Jean. Las Diosas de cada mujer. Una nueva psicología femenina. Barcelona: Kairós, 2001.

SOUZA, Lais et al. Manual de Ginecologia Natural e Autônoma. Salvador-Bahia: las autoras, 2017.

STEINEM, Gloria. "If Men Could Menstruate". Ms Magazine, octubre 1978. Disponible en http:// www.mylittleredbook.net/imcm_orig.pdf. Acceso 02/03/2018.

STYLE, Sofía. Disponible en http://mujerciclica.com/. Acceso 03/04/2018.

RODRIGÁÑEZ BUSTOS, Casilda. Pariremos con placer. Apuntes sobre la recuperación del útero espástico y la energía sexual femenina. Murcia: Ediciones Crimentales, 2009.

TARZIBACHI, Eugenia. Cosa de mujeres. Menstruación, género y poder. CABA: Sudamericana, 2017.

VON REBEUR, Ana. El asunto. La menstruación al desnudo. Buenos Aires: Planeta, 2012. E-book.

VOSTRAL, Sharra Louise. Under wraps. A History of Menstrual Higiene Technology. Plymouth: Lexington Books, 2008.

YOUNG, Iris Marion. On Female Body Experience. "Throwing Like a Girl" and Other Essays. New York: Oxford University Press, 2005.

Núria Calafell Sala (calafell.nur@gmail.com) desarrolla el proyecto "Cuerpos en conflicto en la era del Neoliberalismo: género y procesos de subjetivación”. En el Centro de Investigaciones y Estudios sobre Cultura y Sociedad (CIECS, CONICET y UNC) coordina GREDA-Programa de Feminismos y Estudios de Género. Áreas de especialización: feminismos, cuerpos reproductivos (cuerpos menstruantes y cuerpos maternos, sobre todo) y procesos de subjetivación en los contextos neoliberales contemporáneos.

\section{COMO CITAR ESTE ARTÍCULO, DE ACUERDO CON LAS NORMAS DE LA REVISTA:}

SALA, Núria Calafell. "Menstruación decolonial". Revista Estudos Feministas, Florianópolis, v. 28, n. 1, e57907, 2020.

\section{CONTRIBUCIÓN DE AUTORÍA}

No aplicable

FINANCIACIÓN

No aplicable

CONSENTIMIENTO DE USO DE IMAGEM

No aplicable 


\section{APROBACIÓN DE COMITÉ DE ÉTICA EN INVESTIGACIÓN}

No aplicable.

\section{CONFLICTO DE INTERESES}

No aplicable.

\section{LICENCIA DE USO}

Este artículo está licenciado bajo la Licencia Creative Commons CC-BY Internacional. Con esta licencia se puede compartir, adaptar, crear material para cualquier objetivo, siempre que se le atribuya la autoría.

\section{HISTORIAL}

Recibido el 27/06/2018

Presentado nuevamente el 09/04/2019

Aprobado el 21/05/2019 